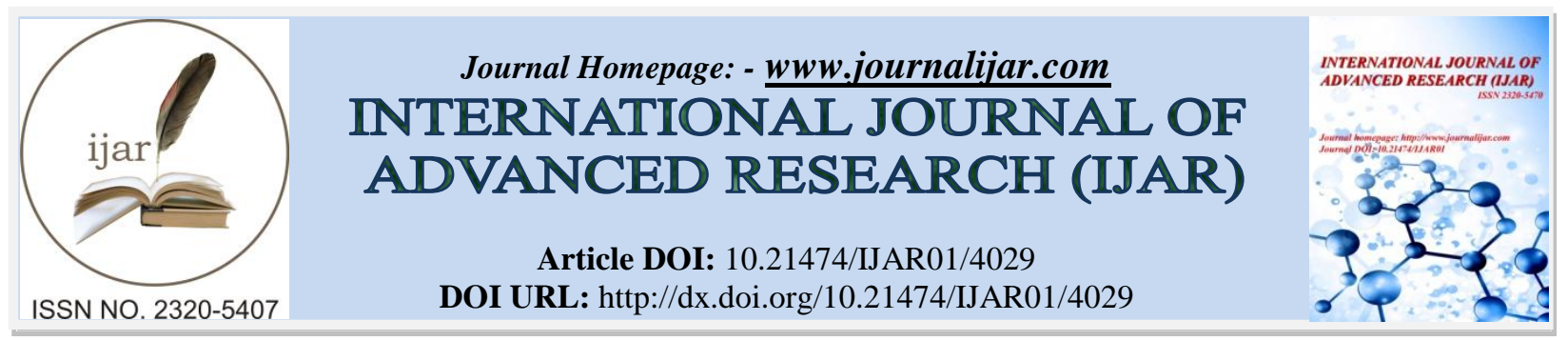

RESEARCH ARTICLE

\title{
BILATERAL CRYPTORCHIDISM: A CASE STUDY.
}

Radha Verma $^{1}$, Kiran Gaikwad ${ }^{2}$, Ishant Chaurasia ${ }^{2}$, Swaroop Anand ${ }^{3}$ and Manali Deosthali ${ }^{4}$.

1. Professor, Unit Head, Department of General Surgery, K.J. Somaiya Hospital, Mumbai, Maharashtra, India.

2. Assistant Professor, Department of General Surgery, K.J. Somaiya Hospital, Mumbai, Maharashtra, India.

3. Resident, Department of General Surgery, K.J. Somaiya Hospital, Mumbai, Maharashtra, India.

4. Intern, Department of General Surgery, K.J. Somaiya Hospital, Mumbai, Maharashtra, India.

\section{Manuscript Info}

Manuscript History

Received: 16 February 2017

Final Accepted: 12 March 2017

Published: April 2017

\section{Abstract}

Cryptorchidism is the absence of one or both testes from the scrotum. It is the most common birth defect of the male genital.The Greek word Kryptos means hidden and Orchis means testicle. It was first described in the medical literature in 1786 by Hunter. The first surgical orchidopexy was attempted in 1820 by Rosenmerkal. However, it was not until 1877 that Annandale performed the first successful orchiopexy.

Copy Right, IJAR, 2017,. All rights reserved.

\section{Introduction:-}

Overall, $3 \%$ of full-term male newborns have cryptorchidism, decreasing to $1 \%$ in male infants aged 6 months to 1 year. The prevalence of cryptorchidism is $30 \%$ in premature male neonates. Two third of these are unilateral and the remaining one third are bilateral.

Factors that predispose to cryptorchidism include prematurity, low birth weight, small size for gestational age, twinning, and maternal exposure to estrogen during the first trimester. Seven percent of siblings of boys with undescended testes have cryptorchidism. Spontaneous descent after the first year of life is uncommon.

\section{Infertility:-}

A reported infertility rate of about $10 \%$ in those with cryptorchidism.

The fertility reduction after orchiopexy for bilateral cryptorchidism is more marked, about $38 \%$, or 6 times that of the general population.

\section{Cancer Risk:-}

About 1 in 500 men born with one or both testes undescended develops testicular cancer, roughly a 4 to 40 fold increased risk. The peak incidence occurs in the 3rd and 4th decades of life.

The risk of malignancy in the undescended testis is 4 to 10 times higher than that in the general population and is approximately 1 in 80 with a unilateral undescended testis and 1 in 40 to 1 in 50 for bilateral undescended testes.

The peak age for this tumor is $15-45 \mathrm{yr}$. The most common tumor developing in an undescended testis is a seminoma (65\%); in contrast, after orchiopexy, seminomas represent only $30 \%$ of testis tumors. 


\section{Case Study:-}

A 19 year old boy came with history of bilaterally abscent testicles from scrotum since birth and a bilateral swelling in the inguinal region since the last 1 month.

On examination, the swelling was $4^{*} 4 \mathrm{~cm}$, non tender,painless and mobile in the inguinal canal It was more palpable in the right mid inguinal ring than the left,which was clinically not palpable.

Consistency was soft Scrotum was empty and no cord structures,omentum or bowel loops were felt.

Secondary sexual characters were normal Axillary and pubic hair present. There was no past surgical history No hist of diabetes,hypertension,tuberculosis in the past USG confirmed bilaterally undescended testes with normal vascularity He was taken up for bilateral orchidectomy with hernioplasty (mesh repair)

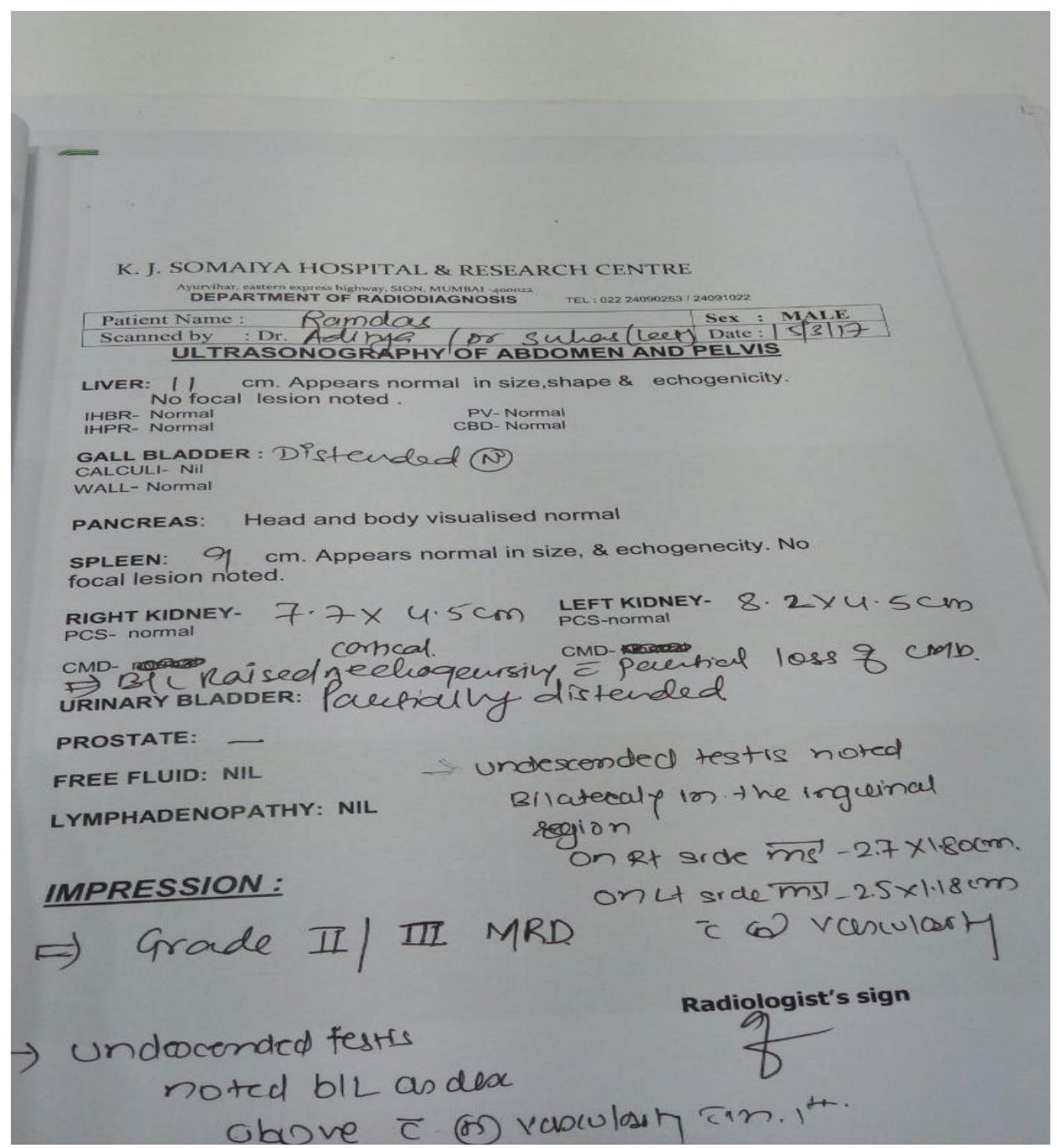




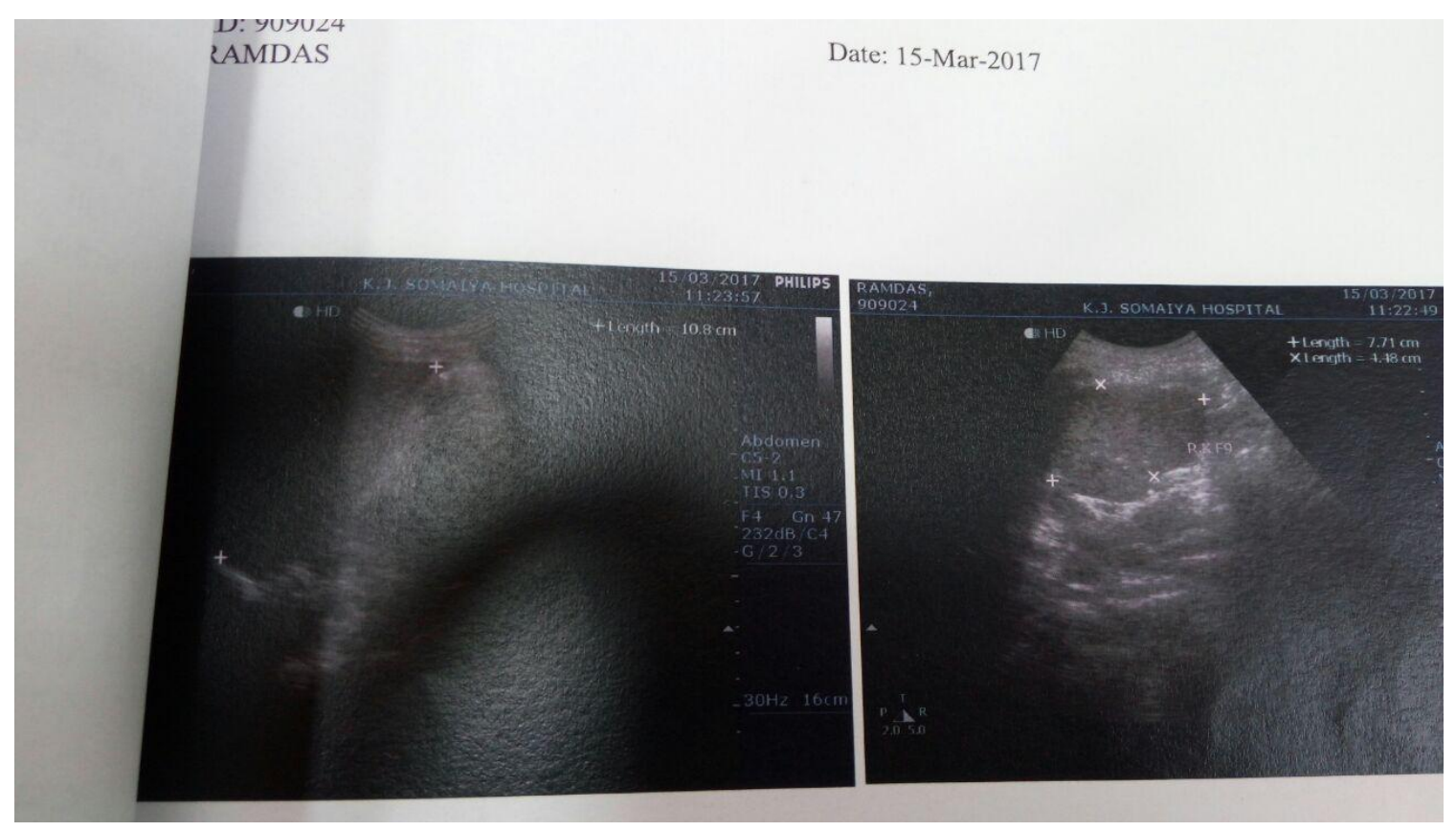

Histopathology report of testis suggested-

Right and left testis measuring $2 * 3 * 3 \mathrm{~cm}$ each with epididymis and spermatic cord and cut section was normal. Microscopically there was no evidence of intratubularneoplasia. Only Leydig cells were seen with no evidence of precursor cells which suggested congenital absence or testicular atrophy.

Impression: germ cell aplasia

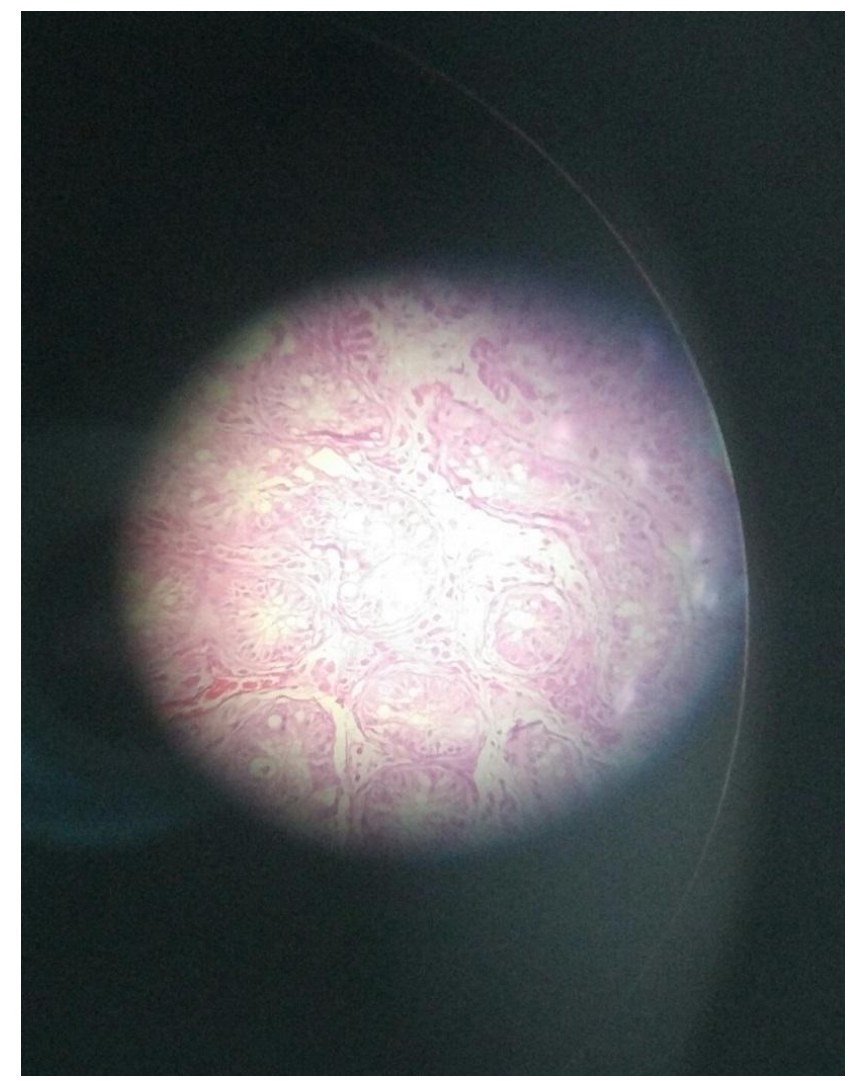




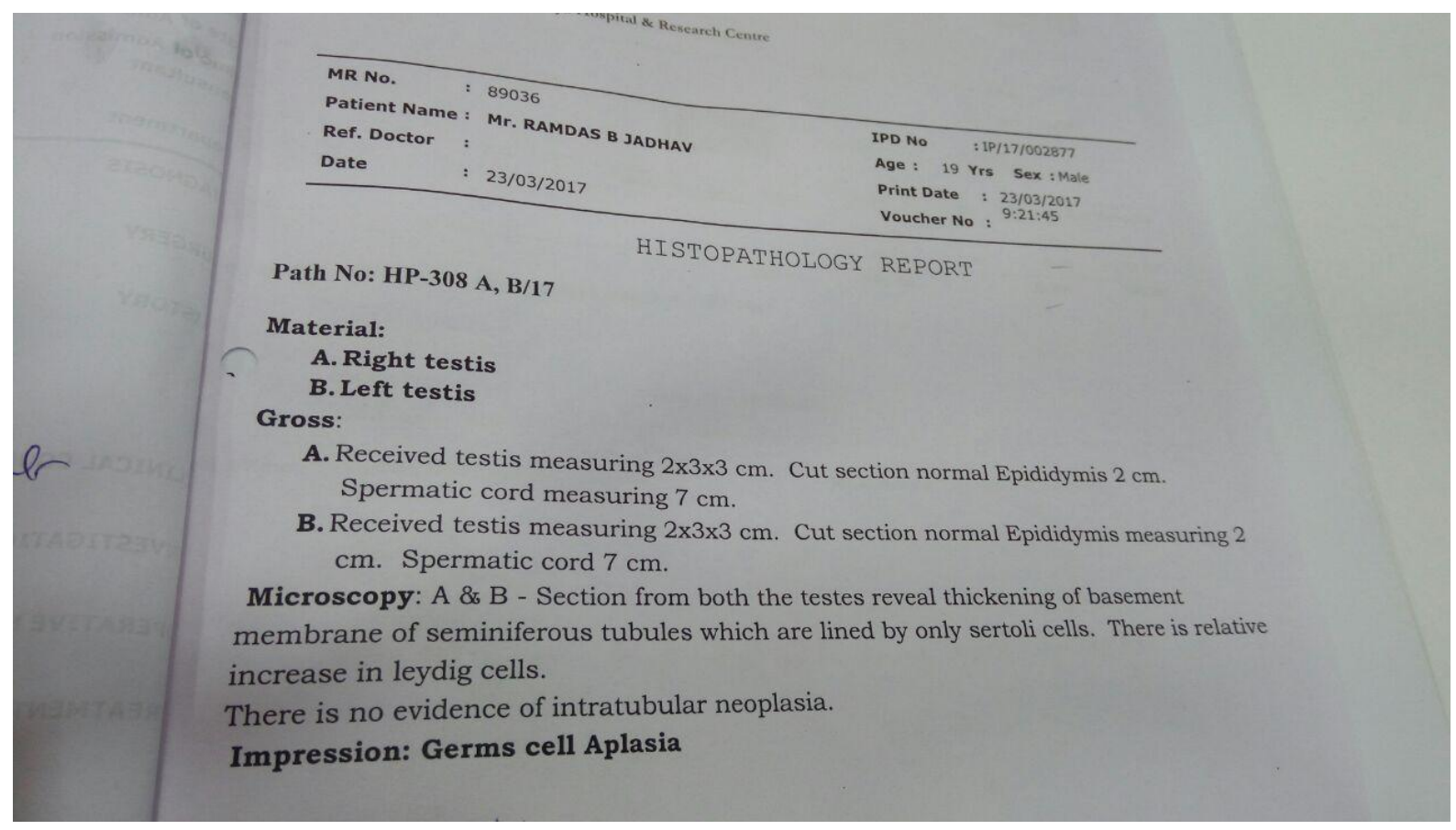

\section{Discussion:-}

\section{Embryology:-}

Normal testicular development begins at conception. The testis-determining factor is now identified as the $S R Y$ gene. The presence of this gene and an intact downstream pathway generally result in testicular formation.

\section{Etiology:-}

Birth weight is the principal determining factor for undescended testes at birth to age 1 year, independent of the length of gestation.

Transabdominal descent of the testis involves differential growth of vertebrae and pelvis until 23 weeks' gestation. Afterward, further descent is facilitated by the development of the gubernaculum, processusvaginalis, spermatic vessels, and scrotum.

Exposure to endocrine-disrupting chemicals may contribute to cryptorchidism, and may account for the increasing incidence rate of cryptorchidism seen in some regions.

Synthetic chemicals identified as endocrine disruptors include phthalates, pesticides, brominated flame retardants, diethylstilbestrol, and dioxins.

Different studies have found conflicting data regarding the involvement of müllerian-inhibiting substance, prenatal estrogen exposure, and descendin (a specific gubernacular growth factor) in the pathophysiology of cryptorchidism.

Intra-abdominal pressure also appears to play a role in testicular descent. Conditions associated with decreased pressure include prune belly syndrome, cloacalexstrophy, omphalocele, and gastroschisis, among other various syndromes.

Cendron and Duckett documented the position upon physical examination and compared this with position at the time of surgery. A testis absent from the normal scrotal position may be:

1. anywhere along the "path of descent" from high in the posterior (retroperitoneal) abdomen, just below the kidney, to the inguinal ring;

2. in the inguinal canal;

3. ectopic, having "wandered" from the path of descent, usually outside the inguinal canal and sometimes even under the skin of the thigh, the perineum, the opposite scrotum, or the femoral canal; 
4. undeveloped (hypoplastic) or severely abnormal (dysgenetic);

5. missing (anorchia)

\section{Diagnosis:-}

In cases with bilaterally non-palpable testes

1. Pelvic ultrasound

2. Magnetic resonance imaging

3. Karyotype can confirm or exclude forms of dysgenetic primary hypogonadism, such as Klinefelter syndrome or mixed gonadal dysgenesis.

4. Hormone levels (especially gonadotropins and AMH) can help confirm that there are hormonally functional testes worth attempting to rescue, as can stimulation with a few injections of human chorionic gonadotropin to elicit a rise of the testosterone level.

\section{Treatment:-}

1. Primary management of cryptorchidism is watchful waiting

2. Hormonal therapy with a series of human chorionic gonadotropin (HCG) injections (10 over 5 weeks).

3. Orchiopexy :

An incision is made over the inguinal canal. The testis with accompanying cord structure and blood supply is exposed, partially separated from the surrounding tissues and brought into the scrotum. It is sutured to the scrotal tissue or enclosed in a "subdartospouch." The associated passage back into the inguinal canal, an inguinal hernia, is closed to prevent re-ascent.

4. Laparoscopy is useful in patients with intra abdominalmaldescended testis to see for oneself the pelvic structures, position of the testis and decide upon surgery.

5. Auto-transplantation of the testis into the scrotum, with all connecting blood vessels anastomosed

The principal major complication of all types of orchiopexy is a loss of the blood supply to the testes resulting in ischemic atrophy.

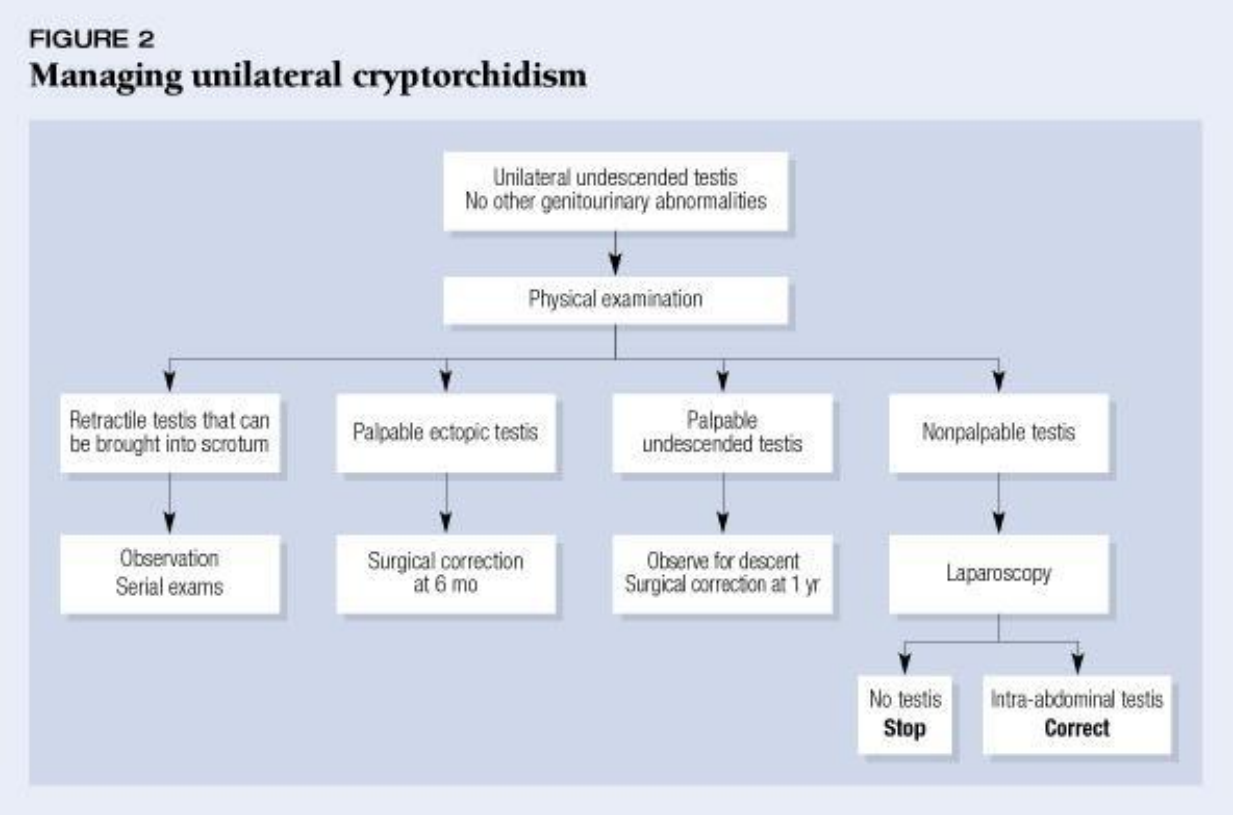




\section{FIGURE 3}

\section{Managing bilateral cryptorchidism}

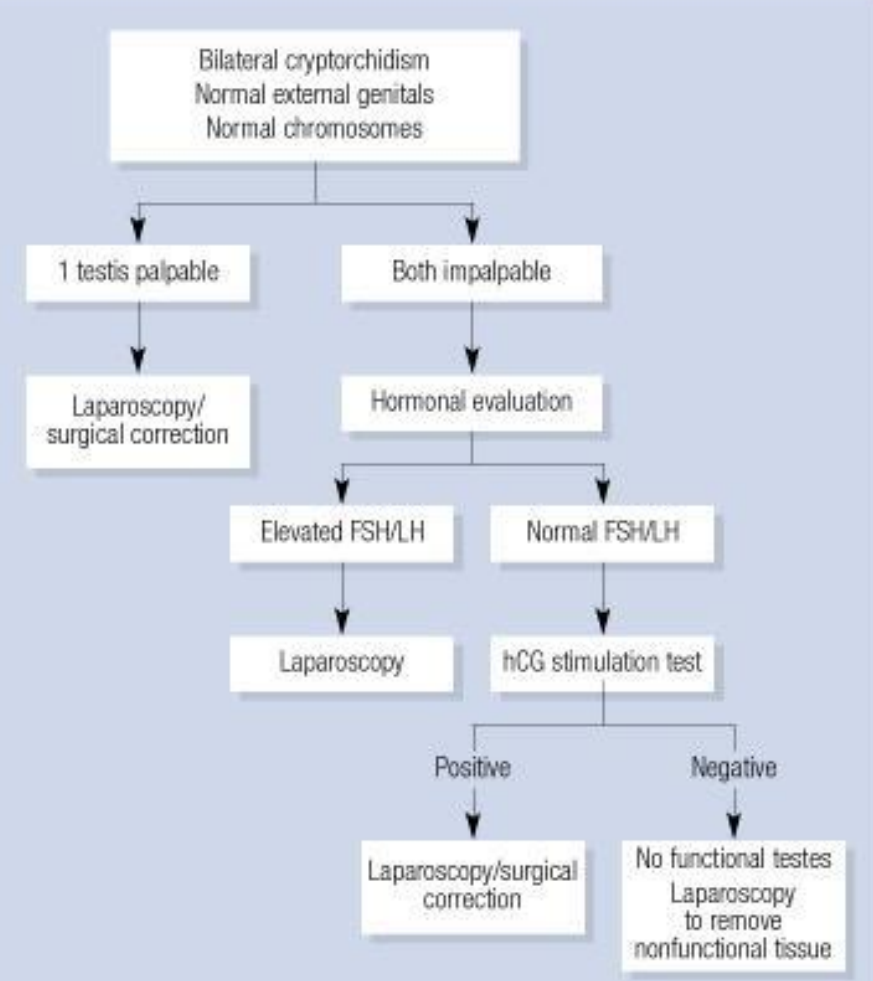




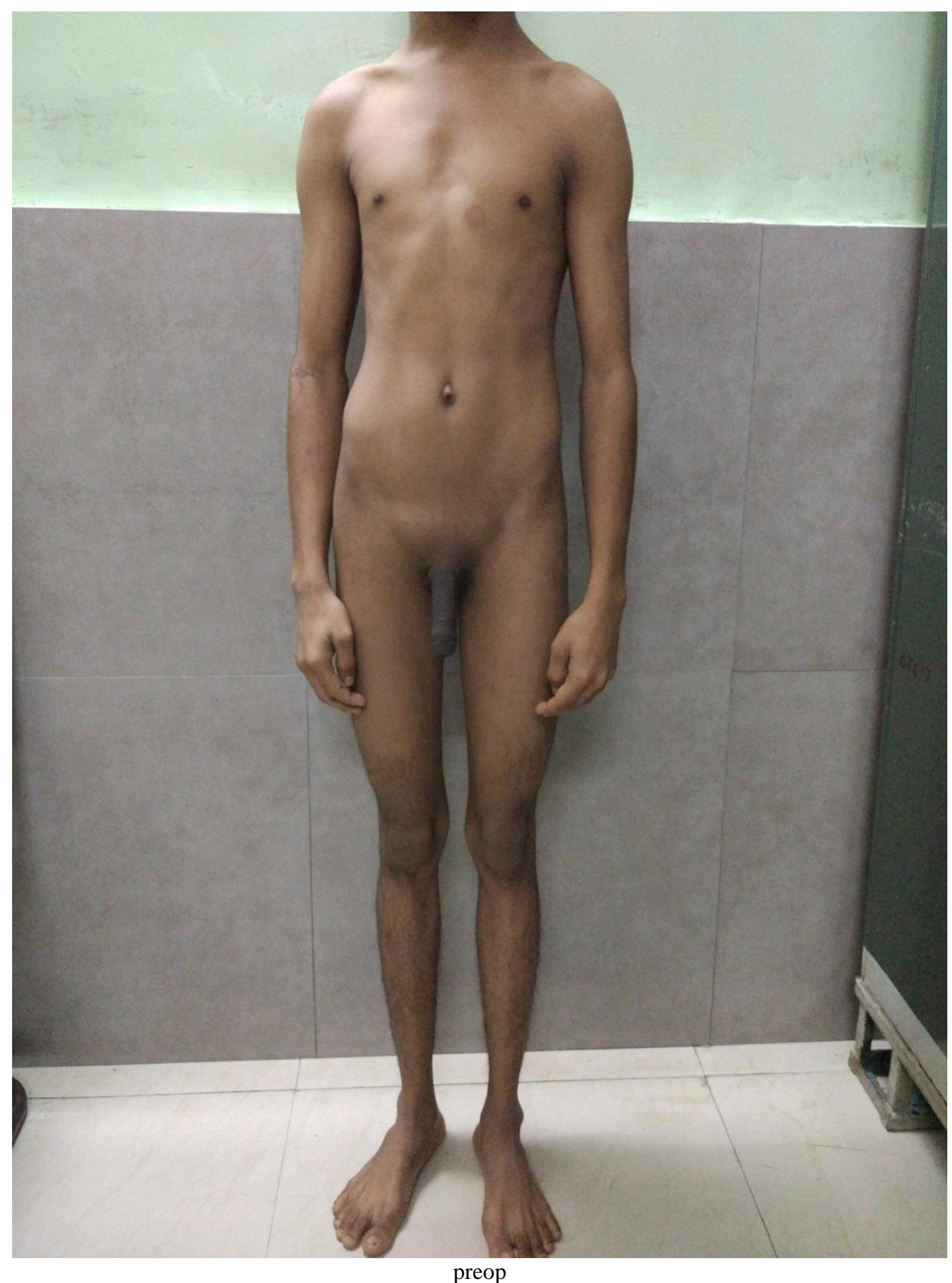




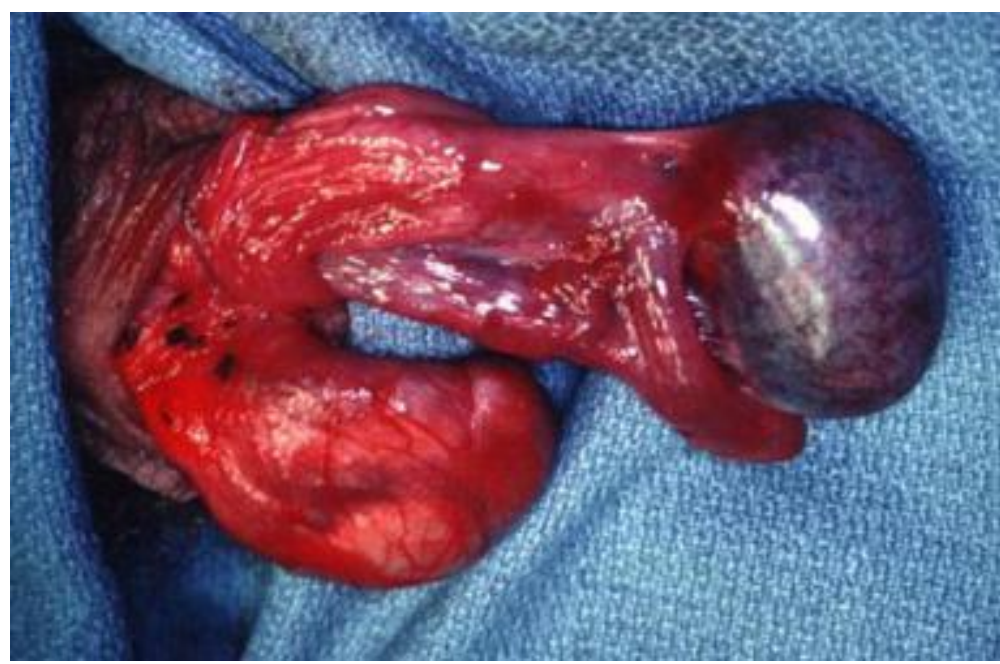

intra op

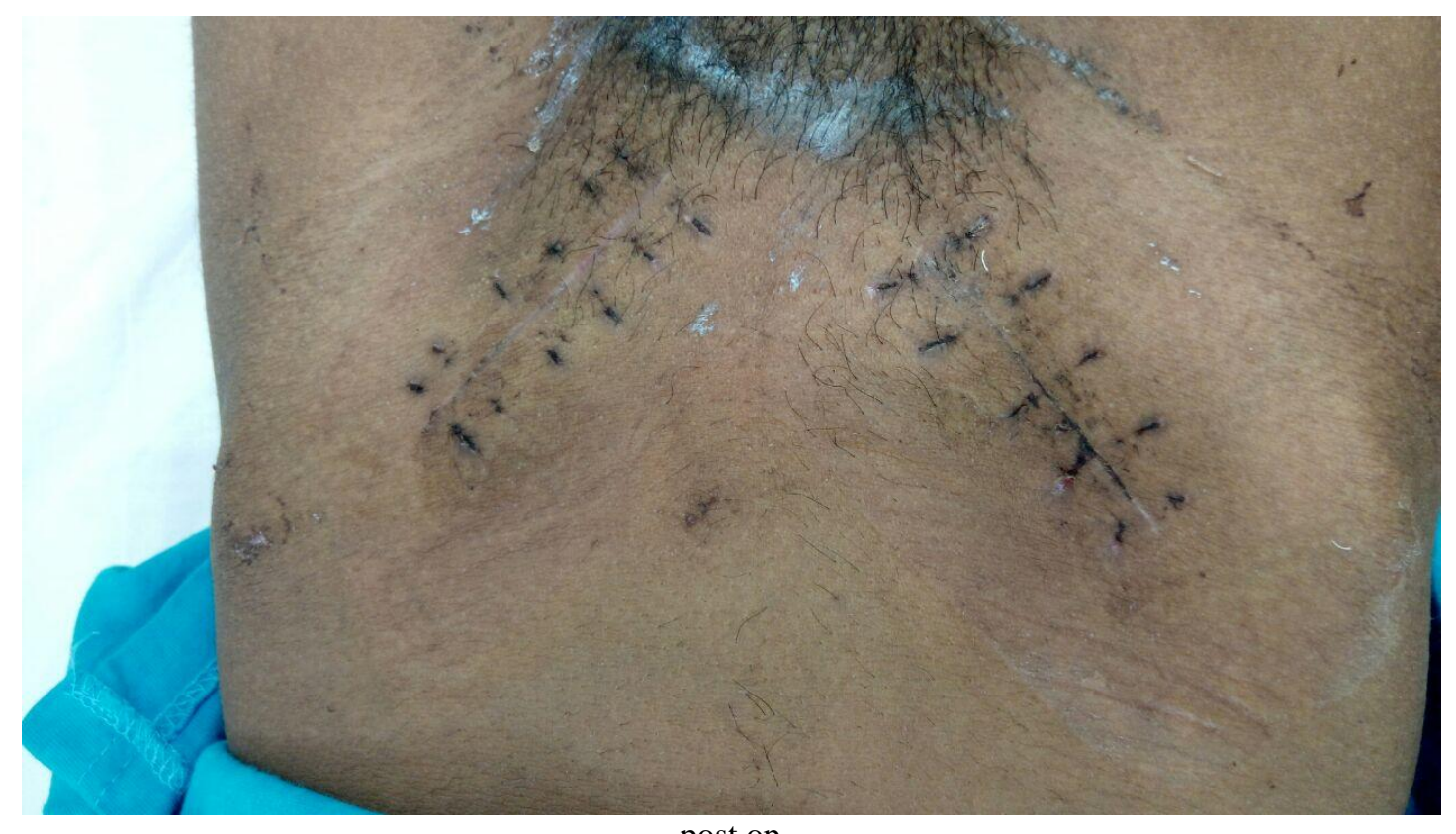

post op

literature:-

SRBs Manual of Surgery, Jaypee Publications Bailey and Love's Short Practice of Surgery S.Das. 